Proc. Indian Acad. Sci., Vol. 88 A, Part I, Number 4, August 1979, pp. 291-296, - printed in India

\title{
Complexes of lanthanide nitrates with $\mathbf{0}, \mathbf{O}^{\prime}, \mathbf{N}$-triisopropyl phosphoramidate
}

\author{
C PREMLATHA and S SOUNDARARAJAN \\ Department of Inorganic and Physical Chemistry, Indian Institute of Science, \\ Bangalore 560012
}

MS roceived 23 February 1979; revisod 19 May 1979

\begin{abstract}
A substitutod phosphoramidate has been used as a ligand to lanthanides for the first time. New complexes of lanthanide nitrates with $\mathrm{O}, \mathrm{O}^{\prime}, \mathrm{N}$-triisopropyl phosphoramidate (TIP) of the general formula $\operatorname{Ln}(\mathrm{TIP})_{2}\left(\mathrm{NO}_{3}\right)_{2}$ where $\mathbf{L n}=\mathbf{L a}$ - $Y b$ and $Y$ have been synthesised and characterised by chemical analysis, infrared and visiblo electronic spectra and olectrical conductance.

Infrarod spectra indicate the coordination of the ligand to the metal ions through the oxygen of the $P=O$ group. IR and conductance show that the nitrate groups are all coordinated. Electronic spectral shapes have been interpreted in terms of an eight coordinate geometry around the metal ions.
\end{abstract}

Keywords. Lanthanide nitrate complexes; triisopropyl phosphoramidate; infrared spectra; visible electronic spectra; electrical conductance.

\section{Introduction}

The coordination of lanthanides with ligands containing $P=O$ groups is not uncommon. Studies on complexes of lanthanides with phosphoramides (Sylvanovich and Madan 1972, Airoldi et al 1976), phosphonates (Stevart and Siddall 1971 ; Mikulski et al 1977), phosphinamides (Vicentini and Braga 1971; Vicentini and Dunstan 1972) and phosphine oxides (Cousins and Hart 1968; Donohogue and Fernandez 1970) have been reported. However, complexes of lanthanides with alkyl phosphoramidates are unknown. In this paper, we report the preparation and characterisation of new adducts of lanthanide nitrates with $\mathbf{O}, \mathbf{O}^{\prime}, \mathbf{N}$ triisopropyl phosphoramidate. The characterisation and assignment of the nature of bonding of the complexes is based on infrared and electronic spectral data, chemical analysis and conductance measurements.

\section{Experimental}

\subsection{Materials}

The rare earth oxides were obtained in $99.9 \%$ purity from Indian Rare Earths Ltd, Kerala. The lanthanide nitrates were prepared by dissolving the appropriate 
oxides in $50 \%$ nitric acid and evaporating the solution to dryness on a water bath. Solvents used were purified by standard methods.

\subsection{Preparation of ligand}

2.2a. Preparation of diisopropyl hydrogen phosphite : Diisopropyl hydrogen phosphite was synthesised by a method similar to that reported by Atherton et al (1945a).

Phosphorous trichloride $(1 \mathrm{mal})$ dissolved in carton tetrachloride $(0.5 \mathrm{~mol})$ was gradually run into isopropanol $(3 \mathrm{~mol})$ in carbon tetrachloride $(2 \mathrm{~mol})$ over a period of 15-20 min with stirring and cooling in an ice salt bath. Then the solution was kept for $90 \mathrm{~min}$ and subjected to reduced pressure. The temperature was raised slowly to remove all the carbon tetrachloride and hydrogen chloride. The residue was distilled at $80-81 \% / 16 \mathrm{~mm}$.

2.2b Preparation of $O, O^{\prime}, N$-triisopropvl phosphoramidate : Triisopropyl phosphoramidate was prepared from the phosphite as reported in literature (Atherton et al 1945b). To the phosphite (1 mol) in 20-25 ml of benzene was added carbon tetrachloride $(1 \mathrm{~mol})$. Isopropylamine $(2.25 \mathrm{~mol})$ was then added dropwise with cooling and stirring and the mixture was then stirred for $2 \mathrm{hr}$, the solid hydrochloride filtered off and the filtrate distilled at $120^{\circ} \mathrm{C} / 6 \mathrm{~mm}$.

\subsection{Preparation of complex}

The complexes were prepared by extraction into carbon tetrachloride. Less than the stoichiometric quantity of ligand in carbon tetrachloride was shaken with the hydrated lanthanide nitrate and boiled for $15 \mathrm{~min}$ on a water bath. After filtering off the unreacted metal nitrate from the carbon tetrachloride solution containing the complex, the solution was evaporated to dryness on the water bath. The resulting oily mass was scratched to obtain the solid complex.

\subsection{Physical measurements}

IR spactra were taken in nujol mulls with a Carl-Zeiss UR-10 spectrometer in the region $400-4000 \mathrm{~cm}^{-1}$. Electronic spectra in solid state in the visible region were recorded with a Unicam SP-700A spectrophotometer. Samples were mulled in nujol and smeared on Whatman filter paper strips. A blank strip smoared with nujol only was used as referencti. Solution spectra in carbon tetrachloride were run on a Beckmann model 25 spectrometer.

\subsection{Analysis}

Metal content of the complexes were determined volumetric lly by EDTA titration using xylenol orange as indicator. The nitrate was estimated gravimetrically as nitron nitrate. Phosphorous was determined colorimetrically as the yellow molybdovanadophosphate complex by the method of Salvago and Dixen (1965).

\section{Results and discussion}

The analytical and conductivity data are summarised in table 1. The adducts are stable and non-hygroscopic for a reasonable length of time. The analytical data 
suggest the formula $\operatorname{Ln}(\mathrm{TIP})_{3}\left(\mathrm{NO}_{3}\right)_{3}$ where TIP $=0, \mathrm{O}^{\prime}, \mathrm{N}$-triisopropyl phospho ramidate, for the complexes. The complexes are soluble in benzene, carbon tetrachloride, chloroform, dimethylsulphoxide and acetonitrile. The electrical conductivity values in acetonitrile show that all the three nitrate groups are coordinated. The important IR bands of the ligand and the complexes along with the assignments are presented in table 2. A considerable shift in the $\mathbf{P}=\mathbf{O}$ stretch to lower frequencies in the complexes compared to that in the ligand clearly proves that the coordination of the ligand to metal ion occurs thrcugh the oxygen of the $\mathbf{P}=\mathbf{O}$ group. In addition shifts to higher frequencies of some of the P-N vibrations are also observed further confirming the coordination through oxygen of the $P=O$ group.

The IR spectra do not show bands indicative of ionic nitrates occurring at $1380 \mathrm{~cm}^{-1}$ and $830 \mathrm{~cm}^{-1}$. Confirmatory evidence for this is provided by conduc tance values. Nitrate groups are capable of bonding to a metal ion in a unidentate or a bidentate fashion. Coordination involving either mode lowers the symmetry of the ionic nitrate from $D_{z a}$ to $C_{2}$. The two situations cannot, in general, be unambiguously distinguished on the basis of the IR data alone. The combination bands of the nitrate group which generally appear in the 1700-1800 region have been used for structural assignments of the nitrate groups (Curtis and Curtis 1965; Lever et al 1971). In the present complexes, we find three weak bands in the said region, the separation between which suggest that both mono and bidentate nitrate groups are present in the complexes.

The strength of the metal nitrate coordination is related to the $v_{4}$ mode of the nitrate group (Carpentier and Moeller 1970). In the TIP complexes of lanthanide nitrates the $v_{4}$ is found between $1505-1520 \mathrm{~cm}^{-1}$. In the complexes of two other $\mathbf{P}=\mathbf{O}$ ligands, viz., diphenyl phosphinyl morpholide (DPPM) (Vicentini et al 1974) and trioctyl phosphine oxide (TOPO) (Manchanda et al 1977), this frequency occurs between $1475-1490 \mathrm{~cm}^{-1}$ and $1485-1510 \mathrm{~cm}^{-1}$ respectively. It

Table 1. Analytical and conductivity data.

\begin{tabular}{|c|c|c|c|c|c|c|c|}
\hline \multirow{2}{*}{ Complex } & \multicolumn{2}{|c|}{ Metal $(\%)$} & \multicolumn{2}{|c|}{ Phosphorus $(\%)$} & \multicolumn{2}{|c|}{ Anion $(\%)$} & \multirow{2}{*}{$\begin{array}{c}\text { Molar } \\
\text { conductance } \\
\mathrm{CH}_{3} \mathrm{CN} \text { at } \\
\left(25^{\circ} \mathrm{C}\right) \\
\left(\mathrm{ohm}^{-1} \mathrm{~cm}^{2}\right. \\
\left.\mathrm{mol}^{-1}\right)\end{array}$} \\
\hline & Found & Theoretical & Found & Theoretical & Found & Theoretical & \\
\hline $\mathbf{L a}$ & $13 \cdot 84$ & 13.98 & 2.99 & $3 \cdot 12$ & $18 \cdot 56$ & $18 \cdot 71$ & $14 \cdot 8$ \\
\hline Pr & 14.03 & $14 \cdot 16$ & $2 \cdot 94$ & $3 \cdot 11$ & $18 \cdot 34$ & $18 \cdot 67$ & $17 \cdot 2$ \\
\hline Nd & $14 \cdot 54$ & $14 \cdot 42$ & 3.01 & $3 \cdot 10$ & $18 \cdot 28$ & $18 \cdot 62$ & $13 \cdot 0$ \\
\hline $\mathrm{Tb}$ & $15 \cdot 51$ & $15 \cdot 68$ & $2 \cdot 89$ & 3.05 & $18 \cdot 19$ & $18 \cdot 34$ & $19 \cdot 4$ \\
\hline Ho & $15 \cdot 98$ & $16 \cdot 17$ & 2.94 & 3.04 & $18 \cdot 03$ & $18 \cdot 24$ & $24 \cdot 0$ \\
\hline $\mathrm{Er}$ & $16 \cdot 28$ & $16 \cdot 39$ & $2 \cdot 88$ & $3 \cdot 03$ & $17 \cdot 95$ & $18 \cdot 20$ & $15 \cdot 6$ \\
\hline $\mathbf{Y b}$ & $16 \cdot 75$ & $16 \cdot 83$ & $2 \cdot 98$ & 3.01 & $17 \cdot 79$ & 18.09 & $17 \cdot 1$ \\
\hline $\mathbf{Y}$ & $9 \cdot 36$ & $9 \cdot 43$ & $3 \cdot 23$ & $3 \cdot 28$ & $20 \cdot 64$ & $20 \cdot 89$ & $21 \cdot 0$ \\
\hline
\end{tabular}


Table 2. Important infrared frequencies (in $\mathrm{cm}^{-1}$ ) and their assignments.

\begin{tabular}{|c|c|c|c|c|c|c|c|c|c|}
\hline Ligand & $\mathbf{L a}$ & $\mathbf{P r}$ & Nd & $\mathrm{Tb}$ & Ho & $\mathrm{Er}$ & $\mathbf{Y b}$ & $\mathbf{Y}$ & Assignmonts \\
\hline & $\begin{array}{l}1770 \mathrm{w} \\
1750 \mathrm{w} \\
1735 \mathrm{w}\end{array}$ & $\begin{array}{l}1770 \mathrm{w} \\
1750 \mathrm{w} \\
1730 \mathrm{w}\end{array}$ & $\begin{array}{l}1770 \mathrm{w} \\
1740 \mathrm{w} \\
1725 \mathrm{w}\end{array}$ & $\begin{array}{l}1770 \mathrm{w} \\
1750 \mathrm{w} \\
1730 \mathrm{w}\end{array}$ & $\begin{array}{l}1775 w \\
1755 w \\
1725 w\end{array}$ & $\begin{array}{l}1775 \mathrm{w} \\
1755 \mathrm{~m} \\
1730 \mathrm{w}\end{array}$ & $\begin{array}{l}1790 \mathrm{w} \\
1750 \mathrm{w} \\
1735 \mathrm{w}\end{array}$ & $\begin{array}{l}1775 w \\
1750 w \\
1735 w\end{array}$ & $\begin{array}{r}\left(v_{2}+v_{3}\right) \\
\text { Nitrate } \\
\left(v_{2}+v_{6}\right) \\
\text { Nitrate }\end{array}$ \\
\hline $\begin{array}{c}\ldots \\
1240 \mathrm{vs} \\
\ldots\end{array}$ & $\begin{array}{l}1520 \mathrm{w} \\
1300 \mathrm{~s} \\
1215 \mathrm{~m} \\
1030 \mathrm{~s}\end{array}$ & $\begin{array}{l}1515 \mathrm{sb} \\
1310 \mathrm{vs} \\
1210 \mathrm{~m} \\
1030 \mathrm{sb}\end{array}$ & $\begin{array}{l}1505 \mathrm{~s} \\
1295 \mathrm{vs} \\
1210 \mathrm{~s} \\
1025 \mathrm{~s}\end{array}$ & $\begin{array}{l}1510 \mathrm{~m} \\
1310 \mathrm{~s} \\
1220 \mathrm{~m} \\
1040 \mathrm{mb}\end{array}$ & $\begin{array}{l}1515 \mathrm{mb} \\
1310 \mathrm{sb} \\
1220 \mathrm{~m} \\
1040 \mathrm{mb}\end{array}$ & $\begin{array}{l}1515 \mathrm{~s} \\
1310 \mathrm{~s} \\
1220 \mathrm{~m} \\
1035 \mathrm{~m}\end{array}$ & $\begin{array}{l}1515 \mathrm{~s} \\
1310 \mathrm{~s} \\
1225 \mathrm{~s} \\
1035 \mathrm{~m}\end{array}$ & $\begin{array}{l}1520 \mathrm{sb} \\
1310 \mathrm{~s} \\
1220 \mathrm{~m} \\
1030 \mathrm{~m}\end{array}$ & $\begin{array}{l}v_{4} \text { Nitrate } \\
v_{1} \text { Nitrate } \\
\mathrm{P}=0 \text { stretching } \\
v_{2} \text { Nitrate }\end{array}$ \\
\hline $\begin{array}{c}995 v s \\
900 s \\
\ldots \\
\ldots\end{array}$ & $\begin{array}{l}1000 \mathrm{~s} \\
910 \mathrm{~m} \\
825 \mathrm{~s} \\
730 \mathrm{w} \\
740 \mathrm{~s}\end{array}$ & $\begin{array}{l}1010 \mathrm{~m} \\
910 \mathrm{~m} \\
820 \mathrm{~s} \\
730 \mathrm{w} \\
740 \mathrm{~s}\end{array}$ & $\begin{array}{l}1005 \mathrm{~s} \\
910 \mathrm{~m} \\
820 \mathrm{~s} \\
730 \mathrm{~m} \\
740 \mathrm{~s}\end{array}$ & $\begin{array}{l}1000 \mathrm{sb} \\
910 \mathrm{~m} \\
825 \mathrm{~s} \\
730 \mathrm{~m} \\
750 \mathrm{~s}\end{array}$ & $\begin{array}{l}1005 \mathrm{~m} \\
910 \mathrm{~m} \\
825 \mathrm{~s} \\
730 \mathrm{~m} \\
750 \mathrm{~s}\end{array}$ & $\begin{array}{l}1010 \mathrm{~m} \\
910 \mathrm{~m} \\
820 \mathrm{~s} \\
730 \mathrm{~m} \\
750 \mathrm{~s}\end{array}$ & $\begin{array}{l}1010 \mathrm{~m} \\
910 \mathrm{~m} \\
820 \mathrm{~s} \\
730 \mathrm{~m} \\
750 \mathrm{~s}\end{array}$ & $\begin{array}{c}1005 \mathrm{~m} \\
910 \mathrm{~m} \\
820 \mathrm{~s} \\
730 \mathrm{w} \\
750 \mathrm{~s}\end{array}$ & $\begin{array}{l}\text { P-N stretching } \\
\text { P-N stretching } \\
v_{8} \text { Nitrate } \\
v_{8} \text { Nitrato }\end{array}$ \\
\hline$\cdots$ & $710 w$ & $710 w$ & $710 w$ & $710 w$ & $710 w$ & $710 w$ & $710 w$ & $710 w$ & $v_{5}$ Nitrate \\
\hline
\end{tabular}

Abbreviations : $v s=$ very strong; $\mathrm{s}=$ strong; $\mathrm{w}=$ weak; $\mathrm{m}=$ medium; $\mathrm{b}=$ broad.

can therefore be suggested that the strength of the metal to nitrate bond in the complexes follows the order TIP $>$ TOPO $>$ DPPM. This order could be related to the bulk of the ligands which increases in the same order. The bulkier the ligand, lesser the chance for the nitrate groups to approach the metal ion and hence weaker the metal-nitrate bond.

The electronic spectral data in the visible region for the $\mathrm{Nd}^{3+}, \mathrm{Ho}^{3+}$ and $\mathrm{Er}^{\text {it }}$ complexes are presented in table 3. The $f-f$ electronic transitions of the lanthanides are found to be sharp and line-like. On complexation, the spectra tend to show band energy shifts as compared to the aquo ion complexes. In the present complexes small shifts to lower frequencies are found for all the bands. This red shift is called the nephelauxetic shift and has been related to covalency in the metal to ligand bond. Sinha $(1966,1971)$ has defined a parameter $\delta$ to measure the covalent character of the metal-ligand bond. This value is given by the relation

$$
\delta(\%)=(1-\beta) / \beta \times 100
$$

where $\beta$ is the average value of the ratio $v_{\text {somplex }} / v_{\text {aquo }}$. The $\beta$ and $\delta$ values calculated for these complexes are presented in table 3 . The $\delta$ values of the TIP complexes are greater than those of oxalates, pthalates and dibenzolymethides reported by Sinha (1966) indicating greater covalency in the metal-ligand bond in the present complexes. However, they are much less compared to the complexes with nitrogen donor ligands such as terpyridyl and dipyridyl. Karraker (1968) has found that the shapes of some of the bands called hypersensitive bands are related to the coordination number around the metal ion. We find that the solid 
Table 3. Electronic spectral data in the visible region for the $\mathrm{Nd}^{3+}, \mathrm{Ho}^{3+}$ and $\mathrm{Er}^{8+}$ complexes.

\begin{tabular}{|c|c|c|c|c|c|}
\hline \multicolumn{2}{|c|}{$\mathrm{Nd}^{2+}$} & \multicolumn{2}{|c|}{$\mathrm{Ho}^{8+}$} & \multicolumn{2}{|c|}{$\mathrm{Er}^{3+}$} \\
\hline J level & Energy (KK) & J level & Energy (KK) & J level & Energy (KK) \\
\hline $\begin{array}{l}{ }^{4} G_{9 / 2} \\
{ }^{4} G_{7 / 2} \\
{ }^{4} G_{5 / 2}\end{array}$ & $\begin{array}{l}19 \cdot 42 \\
18 \cdot 98 \\
17 \cdot 25\end{array}$ & $\begin{array}{l}{ }^{8} G_{6} \\
{ }^{8} G_{5} \\
{ }^{3} K_{6}\end{array}$ & $\begin{array}{l}27 \cdot 55 \\
23 \cdot 92 \\
22 \cdot 10 \\
21 \cdot 98\end{array}$ & $\begin{array}{l}{ }^{4} G_{11 / 2} \\
{ }^{4} F_{3 / 2} \\
{ }^{4} F_{3 / 2}\end{array}$ & $\begin{array}{l}26 \cdot 50 \\
22 \cdot 58 \\
22 \cdot 22\end{array}$ \\
\hline $\begin{array}{c}{ }^{2} G_{7 / 2} \\
. \\
.\end{array}$ & $\begin{array}{c}17 \cdot 15 \\
\ldots \\
\ldots\end{array}$ & $\begin{array}{l}{ }^{6} F_{3} \\
{ }^{6} S_{2},{ }^{5} F_{4} \\
{ }^{6} F_{6}\end{array}$ & $\begin{array}{l}20 \cdot 51 \\
18 \cdot 52 \\
15 \cdot 49\end{array}$ & $\begin{array}{l}4 F_{1,2} \\
{ }^{2} H_{11 / 2} \\
{ }^{4} F_{9,2}\end{array}$ & $\begin{array}{l}20 \cdot 53 \\
19 \cdot 13 \\
15 \cdot 33\end{array}$ \\
\hline \multicolumn{2}{|c|}{$\begin{array}{l}\beta=0.9874 \\
\delta=1.227\end{array}$} & \multicolumn{2}{|c|}{$\begin{array}{l}\beta=0.9949 \\
\delta=0.5126\end{array}$} & \multicolumn{2}{|c|}{$\begin{array}{l}\beta=0.9977 \\
\delta=0.2305\end{array}$} \\
\hline
\end{tabular}

state spectral shapes closely resemble the hypersensitive spectral shapes in solution. This indicates a similarity in coordination number in the solid state and in solution. The shapes of the hypersensitive bands of the $\mathrm{Nd}^{3+}, \mathrm{Ho}^{3+}$ and $\mathrm{Er}^{3+}$ TIP complexes show marked resemblance to the shapes of the aqueous $\mathrm{Nd}^{3+}$, $\mathrm{Ho}^{3+}$ and $\mathrm{Er}^{3+}$ ions in concentrated electrolytes like $\mathrm{LiCl}, \mathrm{HCl}$ where a coordination number of eight has been proposed.

\section{Conclusion}

The analvical, conductivity and infrared data coupled with electronic spectral data indicate that each of the lanthanide ion is surrounded by three TIP ligands coordinating via the oxygen of the $P=O$ group and three nitrate groups. Of the three nitrate groups two are bonded in a bidentate fashion and one in a unidentate fashion. A probable coordination number of eight can thus be assigned on the basis of all these data.

\section{Acknowledgement}

One of the authors (CP) thanks the authorities of the Indian Institute of Science for a fellowship.

\section{References}

Airoldi C, Gushikem Y and Puschel C R 1976 J. Coord. Chem. 617 Atherton F R, Openshaw H T and Todd A R 1945a J. Chem. Soc. p. 382 Atherton F R, Openshaw H T and Todd A R 1945b J. Chem. Soc. p. 660 Carpentier L J and Moeller T 1970 J. Inorg. Nucl. Chem. 323575 Cousins D R and Hart F A 1968 J. Inorg. Nucl. Chem, 303009 
Curtis N F and Curtis Y M 1965 Inorg. Chem. 4804

Donohogue J T and Fernandez E 1970 Bull. Chem. Soc. Jpn. 43271

Karraker D G 1968 Inorg. Chem. 7473

Lever A B P, Mantovani E and Ramaswamy B S 1971 Can. J. Chem. 491957

Manchanda V K, Keshav Chander, Singh N P and Nair G M 1977 J. Inorg. Nucl. Chem. 391039

Mikulski C M, Karayannis N M and Pytlewski L L 1977 J. Less Common Metals 51201

Salvago T and Dixon J P 1965 Analyst 9024

Sinha S P 1966 Spectrochim. Acta 2257

Sinha S P 1971 J. Inorg. Nucl. Chem. 332205

Stewart W E and Siddall III T H 1971 J. Inorg. Nucl. Chem. 332965

Sylvanovich Jr. J A and Madan S K 1972 J. Inorg. Nucl. Chem. 342569

Vicentini G and Braga L S P 1971 J. Inorg. Nucl. Chem. 332959

Vicentini $G$ and Dunstan L PO 1972 J. Inorg. Nucl. Chem. 341303

Vicentini G, Zinner L B and Rothschild L 1974 J. Inorg. Nucl. Chem. 362499 